\title{
The heritage of glatiramer acetate and its use in multiple sclerosis
}

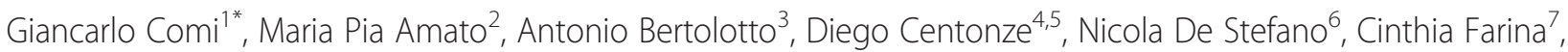 \\ Paolo Gallo ${ }^{8}$, Angelo Ghezzi ${ }^{9}$, Luigi Maria Grimaldi ${ }^{10}$, Gianluigi Mancardi ${ }^{11}$, Maria Giovanna Marrosu ${ }^{12}$, \\ Enrico Montanari ${ }^{13}$, Francesco Patti ${ }^{14}$, Carlo Pozzilli ${ }^{15}$, Leandro Provinciali ${ }^{16}$, Marco Salvetti ${ }^{17}$, \\ Gioacchino Tedeschi ${ }^{18}$ and Maria Trojano ${ }^{19}$
}

\begin{abstract}
Multiple sclerosis (MS) is a chronic and progressively debilitating disease of the central nervous system. Treatment of MS involves disease-modifying therapies (DMTs) to reduce the incidence of relapses and prevent disease progression. Glatiramer acetate (Copaxone ${ }^{\circledast}$ ) was the first of the currently approved DMTs to be tested in human subjects, and it is still considered a standard choice for first-line treatment. The mechanism of action of glatiramer acetate appears to be relatively complex and has not been completely elucidated, but it is likely that it involves both immunomodulating and neuroprotective properties. The efficacy of glatiramer acetate $20 \mathrm{mg} / \mathrm{mL}$ once daily as first-line treatment in relapsingremitting MS is well established, with ample evidence of efficacy from both placebo-controlled and active-comparator controlled clinical trials as well as real-world studies. There is also a considerable body of evidence indicating that the efficacy of glatiramer acetate is maintained in the long term. Clinical trial and real-world data have also consistently shown glatiramer acetate to be safe and well tolerated. Notably, glatiramer acetate has a good safety profile in women planning a pregnancy, and is not associated with foetal toxicity. Until recently, glatiramer acetate was only approved as $20 \mathrm{mg} / \mathrm{mL}$ once daily, but a new formulation with less frequent administration, $40 \mathrm{mg} / \mathrm{mL}$ three times weekly, has been developed and is now approved in many countries, including Italy. This review examines the mechanism of action, clinical efficacy, safety and tolerability of glatiramer acetate to provide suggestions for optimizing the use of this drug in the current MS therapeutic scenario.
\end{abstract}

Keywords: Multiple sclerosis, Glatiramer acetate, Disease-modifying therapy, Pregnancy, Clinically isolated syndrome

\section{Background}

Multiple sclerosis (MS) is a chronic, progressively debilitating disease affecting the central nervous system (CNS). It is characterised by multifocal inflammation leading to demyelination, axonal damage and impaired nerve conduction; MS is usually thought to be an inflammatory, immune-mediated condition in the relapsing phase, but in the chronic progressive phase a neurodegenerative component is predominant [1]. The definition of clinically isolated syndrome (CIS) [2] is used to recognize the first clinical presentation of a disease that could be MS, but has yet to fulfil criteria of dissemination in time.

\footnotetext{
* Correspondence: comi.giancarlo@hsr.it

'Department of Neurology, INSPE, San Raffaele Scientific Institute, Via

Olgettina 48, 20132 Milan, Italy

Full list of author information is available at the end of the article
}

Several disease-modifying therapies (DMTs) are currently available to effectively treat MS, with the aim of abolishing/reducing the number of relapses and preventing disease progression [3]. Due to the chronic nature of the disease, when assessing/exploring the profile of a putative treatment both efficacy and safety have to be examined in the long term [4].

Glatiramer acetate (GA, Copaxone ${ }^{\circ}$ ) was the first of the currently approved drugs to be tested in human subjects with MS [5, 6]. However, the approval of GA by the European Medicines Agency (EMA), at the dose of $20 \mathrm{mg} /$ $\mathrm{mL}$ once daily, subcutaneously administered, dates to 2001, when it joined interferon-beta (IFN- $\beta$ ) in the therapeutic armamentarium. The therapeutic indications are the following: first-line treatment of ambulatory patients with RRMS according to McDonald criteria and treatment of patients who have experienced a CIS and are considered 
at high risk of developing clinically definite multiple sclerosis (CDMS) [7].

Very recently, with the availability of a new GA formulation $(40 \mathrm{mg} / \mathrm{mL}$, injected three times weekly), that was demonstrated to be equally effective as the $20 \mathrm{mg} / \mathrm{mL}$ once daily dose in patients with RRMS [8] and was approved both by the EMA and the Food and Drug Administration (FDA), a substantial gain in patients' quality of life has been achieved. The aim of this review is examining the mechanism of action, clinical efficacy, safety and tolerability profiles of GA to provide suggestions for optimizing the use of this drug in the current MS therapeutic scenario.

\section{Mechanism of action}

The mechanism of action of GA in MS is complex, likely involving an interplay of immunomodulating and neuroprotective properties, with details still to be fully elucidated [9-13] (Fig. 1).

GA was originally designed by researchers at the Weizmann Institute in Israel as a synthetic analogue of myelin basic protein (MBP, an autoantigen implicated in the pathogenesis of MS), with the aim of using it as a molecular mimic of MBP to study the biology of experimental autoimmune encephalomyelitis (EAE), an animal model of MS [14]. GA is a standardised mixture of polypeptides randomly polymerized from four L-amino acids,

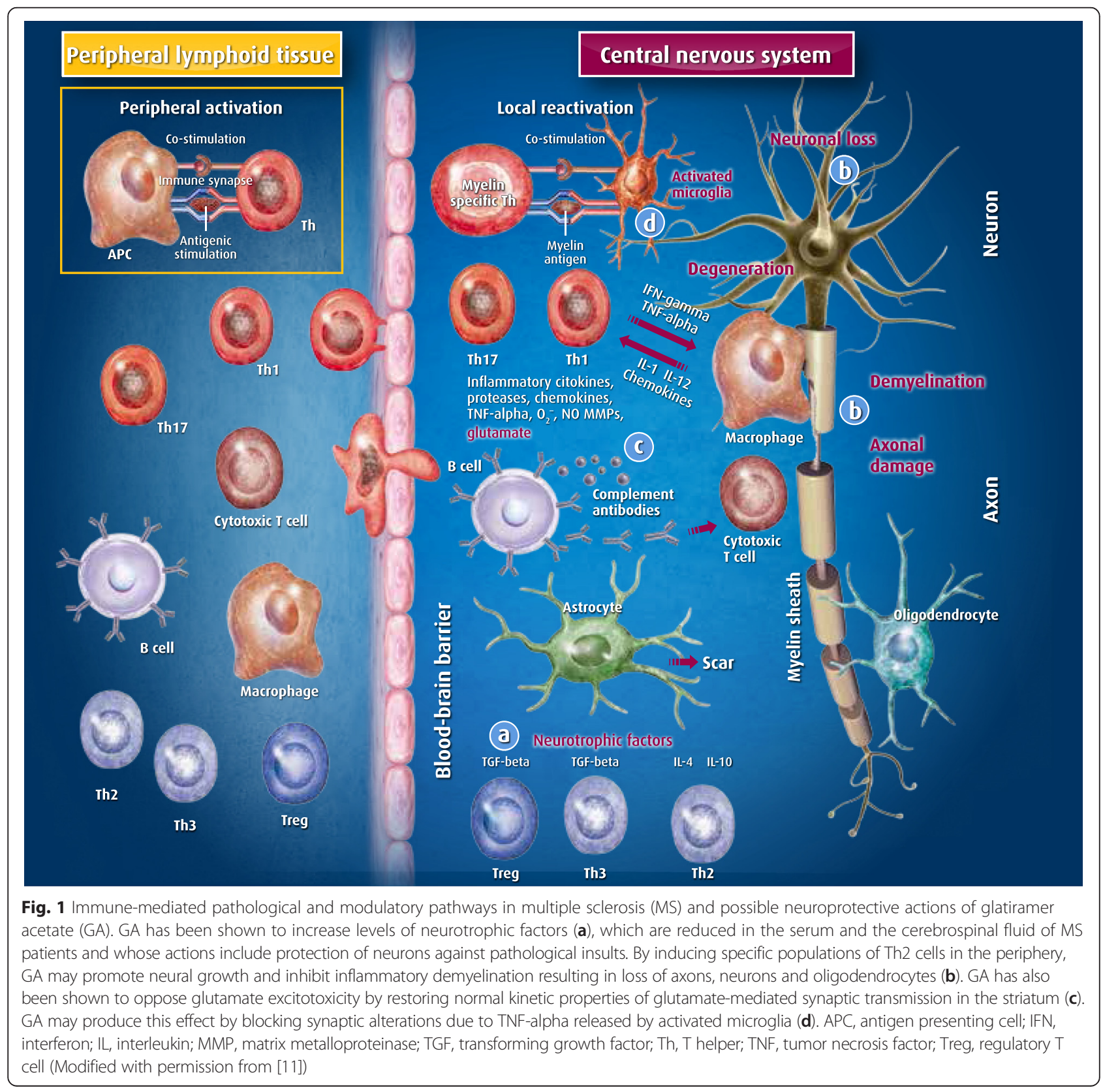


L-glutamic acid, L-lysine, L-alanine and L-tyrosine, in a defined molar residue ratio of 0.14:0.34:0.43:0.09. The same ratio is found in the amino acid sequence of MBP. The molecular mass of the constituent polypeptides of GA ranges from 4.7 to $11 \mathrm{KDa}$.

The researchers found that, surprisingly, the synthesised analogue did not induce EAE, but instead suppressed its development after exposure to crude myelin preparations [15]. This finding encouraged studies focussing on potential competition between GA and MBP in various immune cell-related events, especially in binding to major histocompatibility complex (MHC) molecules and T-cell antigen receptors $[16,17]$. However, it should be noted that these results were mostly obtained using in vitro test systems, and their relevance to the mechanism of action of GA in vivo is uncertain. Aharoni and colleagues also reported that GA can block the proliferation of MBP-reactive T lymphocytes [18], but this finding was not reliably reproduced in subsequent studies. In fact, more recently, it has been shown that GA does not alter the proliferation of MBP-reactive $\mathrm{T}$ cells, but some GA-reactive T cells (specifically the Th2 cells) can respond to MBP by secreting protective cytokines [19]. GA-specific T cells, being able to cross the blood-brain barrier (while the drug itself is not) mediate the activity of GA in the central nervous system (CNS). Moreover GAactivated $\mathrm{T}$ cells are able to suppress EAE induced not only by MBP, but also by other encephalitogens, such as proteolipid protein (PLP) and myelin oligodendrocyte glycoprotein (MOG): this so-called "bystander suppression mechanism" is considered an essential component of the mechanism of action of GA [20].

An important immunomodulatory effect of GA - and possibly the primary mechanism behind its activity - is the induction of a shift in the phenotype of reactive T cells from a mostly pro-inflammatory Th1 pattern of cytokine secretion to a mostly anti-inflammatory Th2 pattern involving the production of IL-4, IL-5, IL-13, IL-10 and TGF- $\beta$ [19, 21-27]. However, even if this is probably the most important mechanism of action of GA, other biological effects have been reported.

The role of Th17 cells (a subset of T cells that produce a distinct profile of proinflammatory cytokines, including interleukin [IL]-17, IL-6, IL-9, IL-21, IL-22, IL-23, IL-26 and tumour necrosis factor- $\alpha$ [TNF- $\alpha]$ ) in the immunopathogenesis of MS and EAE has recently been elucidated [28-30]. GA was found to reduce Th-17-related neuroinflammation and levels of IL-17 and IL-6 in EAE mice [31, 32].

Studies have shown that, in addition to Th17 cells, GA acts on regulatory $\mathrm{T}$ (Treg) cells, whose role in suppressing autoimmunity is well recognized [33]. Patients with RRMS have an impaired CD4+ CD25+ Treg cells-related suppressive capacity [34], and functional alterations of
Treg cells in RRMS may be associated with decreased expression of scurfin, a product of the transcription factor forkhead box P3 (Foxp3) [35]. GA can increase Foxp3 expression, and in vitro studies have shown that exposure of peripheral CD4+ T cells from healthy humans or GAimmunized mice to GA results in an increase in regulatory $\mathrm{T}$ cells, via activation of Foxp3 [36]. A similar finding was reported in a small study in RRMS patients, in which treatment with GA for up to 6 months increased total Treg numbers and reversed the Treg defect [37].

Additionally, it has been demonstrated that GA may act to cause a switch in the B cell phenotype of patients with MS, leading to the development of low but significant titres of GA-reactive IgG4 antibodies [38]. Because the isotype switch to IgG4 in B cells requires IL-4, an important anti-inflammatory cytokine, this finding further supports the anti-inflammatory action of GA in treated patients.

There is also evidence to suggest that GA, in addition to its action on the adaptive immune system, acts on the innate immune system by directly modulating the activity of myeloid cells, in particular monocytes and dendritic cells [39-42]. The properties of monocytes of RRMS patients undergoing treatment with GA have been compared with those of untreated patients and of healthy controls, showing that monocyte reactivity was inhibited in the treated patients. This study is important since it was the first to demonstrate this effect in human subjects treated with GA [43].

A number of studies have also addressed the question of the possible neuroprotective effects of GA. The results of in vitro and animal model studies have shed some light on the possible mechanisms of these effects. In addition to inducing an anti-inflammatory milieu in the CNS through the action of reactive $\mathrm{T}$ cells, GA has been shown to increase levels of neurotrophic factors such as brain-derived neurotrophic factor (BDNF), the actions of which include protection of neurons against pathological insults $[11,44]$. Another possible neuroprotective action of GA, against glutamate excitotoxicity, was recently reported in a mouse model of MS [45]: GA was found to restore normal kinetic properties of glutamate-mediated synaptic transmission in the striatum of treated animals, contrasting the excessive glutamate action on postsynaptic receptors. GA produces this effect (independently of its immunomodulatory action) possibly by blocking synaptic alterations induced by activated microglia-released TNF- $\alpha$.

The induction of specific populations of Th2 cells in the periphery by GA may lead to an environment favouring axonal protection, neural growth and remyelination, as reported in an in vitro and in vivo study by Skihar and colleagues [46]. Exposure of mouse embryonic forebrain cells in culture to GA-reactive $\mathrm{T}$ cells resulted in increased levels of insulin-like growth factor-1 (IGF-1) and promoted 
the formation of oligodendrocyte precursor cells (OPC). Subsequently, mice subjected to induced demyelination of the spinal cord were treated with GA; after 7 days, increased OPC generation and remyelination were observed, associated with higher levels of IGF-1 and BDNF in the spinal cord.

Some observations from clinical trials seem to support such effects. In a substudy of the PreCISe trial, patients treated with GA had increased brain concentrations of the neuronal integrity marker $\mathrm{N}$-acetylaspartate, and an improvement in brain neuronaxonal integrity, whereas patients receiving placebo did not [47]. Also, magnetic resonance imaging (MRI) studies have demonstrated the ability of GA to reduce the proportion of new T1 hypointense lesions evolving into permanent black holes (markers of irreversible axonal loss), therefore supporting the neuroprotective scenario $[48,49]$.

\section{Clinical efficacy}

Subcutaneous GA has a long history of use for the treatment of RRMS. The initially approved dose, on the basis of animal studies, is $20 \mathrm{mg} / \mathrm{mL}$ once daily; still widely considered as standard, it was a keystone for all later drug development. Attempts to explore higher weekly doses (40 $\mathrm{mg} / \mathrm{mL}$ once daily) showed no additive benefit $[50,51]$. Recent results of the GALA study [8] indicate that maintaining a similar weekly dose, but with a different dosing regimen $(40 \mathrm{mg} / \mathrm{mL}$ three times a week), provides advantages in clinical use without impacting on efficacy.

The feasibility of oral administration of GA was tested in the placebo-controlled CORAL trial [52]. Patients with RRMS received $50 \mathrm{mg}$ or $5 \mathrm{mg}$ of GA or placebo daily for 14 months. Neither dose of GA affected the primary endpoint (relapse rate) or any other clinical and MRI endpoint. Thus, further development of oral administration was discontinued. GA has been tested in progressive MS with negative results.

\section{Once-daily formulation \\ In relapsing-remitting multiple sclerosis}

The efficacy of GA $20 \mathrm{mg} / \mathrm{mL}$ once daily as first-line treatment in RRMS is well established in many phase II, III and IV studies.

Placebo-controlled trials The efficacy of GA on clinical and MRI-assessed outcomes has been demonstrated in two major pivotal placebo-controlled trials the US Glatiramer Acetate trial [53] and the European/ Canadian MRI study [54], and supported by an initial small study in 50 patients [55] (Table 1). This latter study provided the first clinical evidence supporting GA in RRMS, with 2 years of treatment with GA $20 \mathrm{mg} / \mathrm{mL}$ daily resulting in a significant difference in the proportion of patients experiencing no relapses versus placebo
(56\% vs. $26 \% ; p=0.045$ ) [55]. The first pivotal trial, the US Glatiramer Acetate phase III study, provided clear evidence for the efficacy of GA, demonstrating a significant $29 \%$ reduction favouring GA in annualised relapse rate (ARR) ( 0.59 vs. 0.84 for placebo; $p=0.007)$, supported by trends in the proportion of relapse-free patients $(33.6 \%$ vs. $27.0 \%$, respectively), and the median time to first relapse (287 vs. 198 days, respectively), after 2 years of treatment [53] (Table 1). In this study MRI measures were not used. A second study, the European/Canadian MRI trial, was planned in order to better define the profile of efficacy and safety of GA. It provided for the first time MRI evidence of the beneficial effect of GA; 9 months of therapy resulted in significant differences favouring GA versus placebo for most endpoints: mean total number of enhancing lesions on T1-weighted images (primary endpoint; 25.96 vs. $36.80 ; p=0.003$ ), number of new enhancing lesions (17.4 vs. $26.0 ; p<0.003)$ and their change of volume $(p<0.01)$, number of new lesions detected on T2weighted images $(9.4$ vs. 13.5 , respectively; $p<0.003)$ and their change of volume $(p=0.001)$. Moreover, a significant reduction of the relapse rate was reported in the GA group versus placebo (33\%; $p=0.012$ ) (Table 1). A later study that analysed MRI data from the EuropeanCanadian trial using a fully automated, normalized method also showed a significant ( $p=0.037$ at 18 months) reduction in the development of brain atrophy in the GA group versus placebo [56]. A noteworthy finding of the European/Canadian MRI study was a reduction in severity of tissue disruption in newly-formed lesions with GA [48]: the percentage of new lesions evolving into permanent black holes was significantly lower in patients treated with GA than in those receiving placebo at 7 months $(18.9 \%$ vs. $26.3 \%$, respectively; $p=0.04)$ and at 8 months $(15.6 \%$ vs. $31.4 \%$, respectively; $p=0.002$ ) after lesion appearance.

Active comparator-controlled trials GA has been compared head-to-head with high-dose subcutaneous IFN- $\beta 1$ a or $-1 \mathrm{~b}$ in two double blind trials in patients with RRMS: REGARD [57] and BECOME [58] (Table 1). Both showed comparable efficacy between GA and IFN- $\beta 1 \mathrm{a}$ or $-1 \mathrm{~b}$. Moreover in the REGARD trial, GA was found to better protect against brain-volume loss $(-1.07 \%$ vs. $-1.24 \%$; $p=0.018)$. These data were confirmed by two trials in which GA was used as reference comparator. In the BEYOND trial [59], two arms receiving IFN- $\beta 1 \mathrm{~b}(250 \mu \mathrm{g}$ and $500 \mu \mathrm{g}$ ) were included, along with a third arm receiving GA: no significant differences were found between groups either in the primary endpoint (ARR: 0.33 for IFN- $\beta 1 \mathrm{~b}$ $500 \mu \mathrm{g}, 0.36$ for IFN- $\beta 1 \mathrm{~b} 250 \mu \mathrm{g}$ and 0.34 for GA; $p=\mathrm{ns}$ for all comparisons) and in all other clinical outcomes (Table 1). The CONFIRM trial [60] compared two doses of dimethyl fumarate versus placebo, again with a third 
Table 1 Clinical trials

\begin{tabular}{|c|c|c|c|}
\hline Study & Number of patients & Trial length & Key outcomes \\
\hline \multicolumn{4}{|l|}{ Placebo-controlled trials } \\
\hline Johnson et al. 1995 [53] & 251 randomised 1:1 GA:PBO & 2 years & $\begin{array}{l}\text { Mean relapse rate: GA } 1.19 \text { versus PBO 1.68; } p=0.007 \text { ( } 29 \% \text { reduction) } \\
\text { (ARR: GA } 0.59 \text { versus PBO 0.84) }\end{array}$ \\
\hline Comi et al. 2001 [54] & 239 randomised 1:1 GA:PBO & 9 months & $\begin{array}{l}\text { Mean reduction in total enhancing lesions GA vs PBO }-10.8 \\
(95 \% \mathrm{Cl}-18.0 \text { to }-3.7 ; p=0.003) ; 29 \% \text { reduction. }\end{array}$ \\
\hline Bornstein et al. 1987 [55] & 50 randomised 1:1 GA:PBO & 2 years & Proportion of relapse-free patients GA $56 \%$ vs $26 \%$ PBO; $p=0.045$ \\
\hline \multicolumn{4}{|c|}{ Active comparator-controlled trials } \\
\hline $\begin{array}{l}\text { Mikol et al. } 2008 \text { [57] } \\
\text { (REGARD) }\end{array}$ & 764 randomised 1:1 GA:IFNß-1a & 96 weeks & $\begin{array}{l}\text { No between-group difference in time to first relapse (HR 0.94; } 95 \% \mathrm{Cl} \\
0.74-1.21 ; p=0.64)\end{array}$ \\
\hline $\begin{array}{l}\text { Cadavid et al. } 2009 \text { [58] } \\
\text { (BECOME) }\end{array}$ & 75 randomised 1:1 GA: INF- $\beta 1 b$ & 2 years & $\begin{array}{l}\text { Similar median }\left(75^{\text {th }} \text { percentile) CAL count per scan in }\right. \\
\text { months } 1-12 \text {, of } 0.58(2.45) \text { vs } 0.63(2.76)\end{array}$ \\
\hline $\begin{array}{l}\text { O'Connor et al. } 2009 \text { [59] } \\
\text { (BEYOND) }\end{array}$ & $\begin{array}{l}2447 \text { randomised 2:2:1 } 250 \mu \mathrm{g} \\
\text { IFN } \beta-1 \mathrm{~b}: 500 \mu \mathrm{g} \text { IFN } \beta-1 \mathrm{~b}: G A\end{array}$ & 3.5 years & No between-group differences in relapse risk or EDSS progression \\
\hline $\begin{array}{l}\text { Fox et al. } 2012[60] \\
\text { (CONFIRM) }\end{array}$ & $\begin{array}{l}\text { Randomised 1:1:1:1 PBO: BG-12 } \\
\text { twice daily:BG-12 three times } \\
\text { daily:GA }\end{array}$ & 96 weeks & $\begin{array}{l}\text { ARR significantly lower with twice-daily BG-12 (0.22), three times-daily } \\
\text { BG-12 (0.20), and GA (0.29) than PBO (0.40) (RR GA } 29 \%, P=0.01) \text {. }\end{array}$ \\
\hline \multicolumn{4}{|l|}{ Combination trials } \\
\hline $\begin{array}{l}\text { Goodman et al. } 2009 \text { [85] } \\
\text { (GLANCE) }\end{array}$ & $\begin{array}{l}110 \text { randomised 1:1 GA + NTZ } \\
\text { versus GA alone }\end{array}$ & 6 months & $\begin{array}{l}\text { Mean rate of development of new active lesions over the } 24 \text {-week } \\
\text { study lower with combination therapy (0.03) vs GA alone (0.11; } \\
p=0.031)\end{array}$ \\
\hline $\begin{array}{l}\text { Lindsey et al. } 2012 \text { [116] } \\
\text { (CombiRx) }\end{array}$ & $\begin{array}{l}1008 \text { randomised 2:1:1 IFN + GA: } \\
\text { IFN: GA }\end{array}$ & 3 years & $\begin{array}{l}\text { No difference in ARR between combination group and GA group } \\
\text { (0.12 vs. } 0.11) \text {. Both combination and GA alone superior to IFN group } \\
(0.16 ; p=0.022 \text { for combination group and } p=0.027 \text { for GA group) }\end{array}$ \\
\hline \multicolumn{4}{|l|}{ Clinically isolated syndrome } \\
\hline $\begin{array}{l}\text { Comi et al. } 2009 \text { [86] } \\
\text { (PreCISe) }\end{array}$ & 481 randomised 1:1 GA:PBO & 36 months & $\begin{array}{l}\text { GA reduced risk of CDMS by } 45 \% \text { versus PBO (HR } 0.55,95 \% \mathrm{Cl} \\
0.40-0.77 ; p=0.0005)\end{array}$ \\
\hline
\end{tabular}

$95 \% \mathrm{Cl} 95 \%$ confidence interval, ARR Annualised relapse rate, CAL Combined active lesions, CDMS Clinically definite multiple sclerosis, EDSS Expanded disability status scale, GA Glatiramer acetate, HR Hazard ratio, IFN Interferon, NTZ natalizumab, PBO Placebo, RR Relative risk

arm with GA as a reference comparator. Even if the design of the trial did not allow a comparison between the two active treatments, both drugs proved to be significantly superior to placebo in all clinical and MRI outcomes (Table 1). In particular, GA significantly reduced the ARR versus placebo by $29 \%$ $(p=0.01)$, thus confirming the results of the pivotal trials in a very large population sample (over 1400 patients). A post hoc subgroup analysis reported numerically similar relapse-related outcomes between the two dimethyl fumarate arms and the GA arm in most patient subgroups [61].

A systematic review summarising data from five randomised studies comparing IFN- $\beta$ with GA in patients with RRMS confirmed a similar efficacy after 2 years of treatment [62].

Long-term and real-word data Even with all the limitations of long-term extension studies, due to potential selection bias, available data suggest that the efficacy of GA is maintained over time [63-71]. Moreover, there have been no reports of rebound effect or delayed disease reactivation after treatment discontinuation in extensions of clinical trials or postmarketing studies [63, 70, 72, 73].

The first follow-up of the US Glatiramer Acetate trial presented 15-year data [63]. Patients continuing in the study (100 of the initial 232) showed a reduced ARR $(0.25 \pm 0.34$ per year vs. $1.12 \pm 0.82$ at baseline); $57 \%$ had stable or improved Expanded Disability Status Scale (EDSS) scores (change $\leq 0.5$ points) and $67 \%$ showed stable disease, without transitioning to secondary progressive MS. The most frequently reported reasons for treatment discontinuation were patient perception of disease worsening $(n=29)$, a desire to switch or combine therapies $(n=26)$ and difficulty, inability, or unwillingness to adhere to the study protocol $(n=32)$. Twenty-year results are now available for the longterm extension of this study [64]. Of the initial 232 patients, 74 remain in the trial and have been continuously treated for a mean of 19.3 years. Very long-term use of GA appears to be associated with stable disease activity (cumulative ARR $=0.2 ; 24.3 \%$ of patients remained free of relapse for the entire period) and low levels of accumulated disability (mean EDSS score 3.1 vs. 2.4 at baseline). 
The extension of the European/Canadian MRI study offers serial long-term MRI data for a large cohort of patients treated with GA [70]. After the 9-month doubleblind, placebo-controlled phase, all patients entered an open-label, active treatment phase in which they received GA $20 \mathrm{mg} / \mathrm{mL}$ once daily for a further 9 months, with a long-term follow-up visit (LTFU) scheduled at least five years after study entry. Overall, MRI results show that the effects of GA on MS activity are sustained (number of active lesions 0.9 at LTFU vs. 3.4 at baseline; percentage brain volume change -5.02 vs. baseline). Moreover, MRI results in the patients that were shifted from placebo to GA showed a significant reduction of MRI measures of disease activity, paralleling what was observed in the patients that received GA from the start. A notable finding is that the proportion of patients requiring walking aids at the LTFU was significantly lower $(p=0.034)$ in the group that received GA from the start of the study compared with delayed treatment, suggesting that early treatment may have a positive impact on long-term disease outcomes.

A 5-year brain MRI retrospective open study provides some evidence of the efficacy of GA in reducing brain volume loss [74]: smaller reductions in brain volume were observed in patients with RRMS treated with subcutaneous GA than with high-dose IFN- $\beta$ regimens (percentage change in brain volume $-2.27 \%$ vs. $-3.21 \%$; $p<0.0001)$.

Various studies report real-world data for GA treatment in RRMS [72, 73, 75, 76], confirming the efficacy profile of GA observed in the clinical studies. A significant impact of the treatment with GA on health-related quality of life has also been reported [77, 78], with beneficial effects including significant reductions in fatigue and in days of absence from work.

Controlled studies of MS treatments in children and adolescents are still lacking, but some published evidence, albeit retrospective, points to the efficacy of GA in this population. In an Italian cohort, 14 patients with a mean age of 13.1 years were treated for a mean of 5 years or more; these patients had a reduction in relapse rate, from about 3 per year before treatment initiation to $0.2-0.4$ per year during the treatment period [79]. A small study of seven patients with RRMS who had disease onset at 9-16 years of age and began GA before 18 years of age showed that 24 months of treatment resulted in two of seven patients remaining relapse free over the study period, and three of seven patients having stable disability scores as measured by the EDSS [80].

Switching to glatiramer acetate Several trials have evaluated switching to GA from other MS therapies for safety and efficacy reasons [81-83]. For patients not responding to first line therapies GA can be offered as an alternative to so-called second line medications if there are concerns of tolerability/adverse events with the latter therapies. Most studies describe switches from IFN $\beta-1 \mathrm{a}$ or $-1 \mathrm{~b}$ to $\mathrm{GA}$, reporting reductions in mean ARR after switching [81-83]. However, in those situations when the shift is due to failure of the previous treatment, results should be interpreted with caution because the regression to the mean phenomenon is a major concern. Therefore, randomised, controlled trials are needed to confirm these results.

Combination treatment trials Two important combination therapy trials are the CombiRx trial [84] and the GLANCE trial [85] (Table 1). In CombiRx, patients were randomised to GA $20 \mathrm{mg} / \mathrm{mL}$ once daily plus IFN- $\beta 1$ a 30 $\mu \mathrm{g}$ once weekly or to monotherapy with one of these medications plus placebo for 3 years. For the primary outcome of ARR, the combination therapy was significantly superior to IFN- $\beta$, reducing the relapse rate by $25 \%(p=0.022)$, while there was no significant difference between the combination therapy and GA. It should be noted that the study design allowed for the first time a comparison between intramuscular IFN- $\beta$ and GA, with GA resulting superior (relapse rate reduction by $31 \%$ compared with IFN- $\beta ; p=0.027)$. The GLANCE study compared combination therapy with GA $20 \mathrm{mg} / \mathrm{mL}$ once daily plus intravenous natalizumab $300 \mathrm{mg}$ every 4 weeks versus monotherapy with GA $20 \mathrm{mg} / \mathrm{mL}$ once daily plus placebo every 4 weeks. At 24 weeks, the combination therapy was superior on major MRI disease activity measures.

\section{In clinically isolated syndrome}

Early treatment with GA in patients with CIS has been shown to delay onset of CDMS in the placebo-controlled study PreCISe [86] (Table 1) and during its subsequent open-label extension period [87]. The study enrolled 481 patients with one unifocal neurological event and a positive MRI scan (defined as the presence of at least two cerebral lesions $\geq 6 \mathrm{~mm}$ in diameter on T2-weighted images). Patients were randomised to GA $20 \mathrm{mg} / \mathrm{mL}$ once daily or placebo for up to 36 months or until conversion to MS. GA was associated with a $45 \%$ reduction in risk of conversion to MS (primary endpoint; $p=0.0005$ ) and a delay in the time to conversion compared with placebo (336 days vs. 722 days, respectively). GA was associated with a $58 \%$ reduction in number of new T2 lesions and a smaller volume of T2 lesions. During the extension phase (total 5 years' duration) the efficacy of GA was sustained, with a $41 \%$ reduction in risk of conversion to MS in those treated with GA from the start compared with delayed treatment; in the GA group, there was a delay of 972 days before conversion to MS, a $42 \%$ reduction in new T2 lesions per year $(p<0.0001)$ and a $22 \%$ reduction in T2- 
lesion volume $(p=0.0005)$. In the extension phase patients treated with GA from study entry showed a significant $28 \%$ reduction $(p=0.0209)$ in brain volume loss compared with patients initially randomised to placebo, confirming the neuroprotective effects of GA. This is the first trial to demonstrate that early treatment with GA reduces brain atrophy versus delayed treatment in this setting.

\section{In progressive forms of multiple sclerosis}

GA was assessed in primary progressive forms of MS, with negative results. The PROMiSe study [88] was a randomised, double-blind, placebo-controlled, multicentre, international study that investigated the effect of GA on disability progression in 943 patients with progressive MS. After 3 years of treatment, the time to sustained accumulated disability was similar between GA- and placebo-treated patients (hazard ratio [HR] 0.87; $95 \%$ CI 0.71 to $1.07 ; p=0.1753$ ). A post hoc analysis showed a possible effect in slowing clinical progression in male patients (HR 0.71; $95 \%$ CI 0.53 to $0.95 ; p=0.0193$ ) [88], but a subsequent analysis of these results did not demonstrate an impact of gender on the efficacy of GA [89]. An additional study investigating metabolite ratios as determined by MRI in a subset of 58 patients from the PROMISe study showed no difference between the GA and placebo groups [90]. However, it should be noted that the PROMISe study was terminated early due to lack of effect, and that the low rate of disability progression and the high rate of premature discontinuations led to a decrease in power of the study, hampering the determination of a treatment effect [88].

\section{Three times weekly formulation}

The first trial to evaluate a high-dose regimen of GA was the phase III FORTE study [51] that compared the $40 \mathrm{mg} /$ $\mathrm{mL}$ once daily dose with the standard $20 \mathrm{mg} / \mathrm{mL}$ once daily dose in patients with RRMS. Both doses showed similar effects on efficacy measures and no difference in the safety profile. Post-hoc analyses revealed potential benefits of the $40 \mathrm{mg} / \mathrm{mL}$ dose in some subgroups (for example, in the "frequent MRI cohort" patients treated with $40 \mathrm{mg} / \mathrm{mL}$ showed a slight numerical advantage in the reduction of the mean number of gadolinium-enhancing lesions at various timepoints vs. baseline). After this study the development of the high-dose once daily regimen was discontinued, but it provided a starting point for subsequent research on the high-dose, lower-frequency regimen ( $40 \mathrm{mg} / \mathrm{mL}$ three times weekly).

The efficacy of subcutaneous GA $40 \mathrm{mg} / \mathrm{mL}$ three times weekly in patients with RRMS was shown in the 1-year, double blind, placebo-controlled GALA study, involving about 1400 patients [8]. Significant reductions compared with placebo in relapse rate $(34.0 \% ; p<0.0001)$, cumulative number of gadolinium-enhancing T1 lesions $(44.8 \% ; p<0.0001)$ and new or enlarged T2 lesions $(34.7 \% ; p<0.0001)$ were reported; the numerical values of these parameters were very similar to those observed in the pivotal studies with the $20 \mathrm{mg} / \mathrm{mL}$ once daily dose. Three-year results of the open-label extension of the GALA study demonstrated sustained efficacy on ARR and MRI parameters of disease activity [91]. Patients switched from placebo to GA after the double blind phase reported significant gains in efficacy, but those treated with GA from study entry showed a significantly lower relapse rate (ARR 0.23 vs 0.30 , respectively, $p=0.0052$ ) and significantly fewer enhancing T1 lesions and new or enlarged $\mathrm{T} 2$ lesions $(\mathrm{RR}=0.660, p=0.0005$ for $\mathrm{T} 1$; $\mathrm{RR}=$ $0.680, p<0.0001$ for T2) compared with patients with delayed treatment.

An important finding from a recent post hoc MRI analysis of data from the GALA study is that GA $40 \mathrm{mg} / \mathrm{mL}$ three times weekly (cumulative weekly dose of $120 \mathrm{mg}$ ) shares the ability of the standard formulation (cumulative weekly dose of $140 \mathrm{mg}$ ) to reduce conversion of new active lesions into black holes, markers of permanent damage and disability progression, with a significant $24 \%$ reduction compared with placebo $(p=0.006)$ in the odds of conversion from new lesions at month 6 to black holes at month 12 [49].

In the absence of head-to-head studies comparing GA $20 \mathrm{mg} / \mathrm{mL}$ once daily and $40 \mathrm{mg} / \mathrm{mL}$ three times weekly, indirect comparisons have also shown very similar efficacy of the two doses $[92,93]$.

On the same lines, the GLACIER study, in which patients were asked to report the personal experience of shifting from the $20 \mathrm{mg} / \mathrm{mL}$ once daily dose to the $40 \mathrm{mg} /$ $\mathrm{mL}$ three times weekly dose, demonstrated a favourable convenience profile and patient satisfaction when converting from the once-daily formulation [94].

\section{Safety}

After 20 years' continuous clinical use and more than 2 million patient-years' exposure, the safety profile of GA is well established. No evidence of any association of GA with immunosuppression or with malignant and autoimmune disease has been reported after 10 and 15 years follow-up [63, 65]. GA was not associated with psychiatric or mood disorders and in some studies a significant improvement in fatigue was observed, even in patients switching from other DMTs [78]. In a study of patients with RRMS and spasticity, switching from IFN- $\beta$ to GA improved spasm frequency, muscle tone and pain after 3 months of treatment; these improvements were maintained over 6 months of treatment with GA [95]. A few cases of hepatotoxicity during treatment with GA have recently been reported [96-98], with no such cases reported in clinical trials, hence it is unclear at present if 
liver function monitoring is warranted. It should be noted, though, that because some of the patients reporting this $\mathrm{AE}$ had concurrent autoimmune conditions, it is impossible to disentangle the potential contribution of GA treatment and the underlying condition to hepatotoxicity. IgE-mediated allergic reactions have also been described $[99,100]$.

Both formulations of GA appear equivalent from the safety standpoint $[64,91,94]$. In the GALA study AEs associated with administration of GA $40 \mathrm{mg} / \mathrm{mL}$ three times a week were found to be consistent with the known safety profile of GA $20 \mathrm{mg} / \mathrm{mL}$ once daily. Moreover, no new AEs emerged during treatment with high-dose GA $[8,91]$.

At present there are no controlled studies of DMTs in children and adolescents with MS, but published evidence, mostly retrospective studies, support a similar safety profile of GA in this population [79, 80]. GA, along with IFN$\beta$, has been recommended as the standard treatment for paediatric RRMS in two position papers, one produced by European experts [101] and the other one by the International paediatric MS Study [102]. Since paediatric onset MS is characterized by high disease burden, early treatment, although off-label, should be promptly started after confirmation of the diagnosis. The favourable tolerability profile of GA should be considered when making a therapeutic choice [101, 102].

No limitations to concomitant administration of GA and other drugs have been identified; the medication is not linked to blood test abnormalities that require monitoring.

\section{Pregnancy}

Animal reproduction studies have failed to demonstrate a risk of GA treatment to the foetus, and post-marketing studies support the absence of foetal toxicity [103-108]. For these reasons GA has been classified as FDA Class B during pregnancy [109]. Most of the other drugs approved for the treatment of MS are categorized by the FDA as Class $\mathrm{C}$, with the exception of mitoxantrone, classified as Class D (positive evidence of human foetal risk), and teriflunomide, classified as Class X (foetal toxicity) [104, 109]. GA can be continued right up until conception, unlike other DMTs for which a washout period is recommended prior to trying to conceive [104]. GA may also be used as bridging therapy in women planning a pregnancy who are receiving treatments requiring a washout period, if it exposes women to the risk of MS reactivation, and offers some advantages in women risking unplanned pregnancies.

While it is currently recommended that, as for any other DMT, GA should be discontinued after confirmed evidence of pregnancy and until childbirth, available evidence suggests GA could be continued at least throughout the first trimester, while further continuation of GA treatment may be assessed on a case-by-case basis [104]. An Italian retrospective study showed that the mother's exposure to GA when the drug was suspended within 4 weeks from conception was not associated with an increased frequency of spontaneous abortion nor with other negative pregnancy and foetal outcomes compared with women in whom the medication was suspended 4 weeks or more from conception, or who were untreated [107]. These findings confirm those of a previous observational study [106] suggesting that GA and the IFNs do not represent a significant risk for prenatal developmental toxicity. Relapse rate decreases during pregnancy, with a well-known increase in the first three months after childbirth [110] that sometimes requires secondline therapy to be controlled [103-105].

\section{Tolerability}

The tolerability of GA $20 \mathrm{mg} / \mathrm{mL}$ once daily has consistently been reported as good versus both placebo and active treatment in the previously mentioned clinical trials $[54,57,59,86]$, and the nature and frequency of treatment-related AEs were similar between shortand long-term treatment periods [63-65, 67]. The most common $(>1 / 10)$ treatment-related AEs are transient injection-site reactions, occurring occasionally in about two thirds of patients [7]. These include injection site bruising, erythema, pain, pruritus and induration. Rarer cases of localized lipoatrophy and skin necrosis at injection sites have been reported during post-marketing $[111,112]$. One peculiar injection-related tolerability issue with GA is the occurrence of immediate post-injection reactions (IPIR) that present immediately or a few minutes after the injection, consisting in flushing, chest tightness, palpitation, dyspnoea and intense anxiety. The crisis resolves spontaneously in a few minutes [53]. These reactions are unpredictable, affecting about $15 \%$ of patients and seldom recurring more than once. The intensity of the reaction is not connected to any real risk to patients.

The tolerability of GA $40 \mathrm{mg} / \mathrm{mL}$ three times weekly has been shown to be similar to that of the $20 \mathrm{mg} / \mathrm{mL}$ once-daily formulation $[8,91]$. Importantly, in the GLACIER study [94], three times weekly GA was found to be better tolerated than the once-daily formulation in terms of injection-related adverse events (IRAEs): the adjusted mean annualized rate of IRAEs was reduced by $50 \%$ in patients receiving the new formulation (35.3 events per year vs. 70.4 events per year, respectively; $p=0.0006$ ), while the rate of moderate/severe events was reduced by $60 \%$ ( 0.9 events per year vs. 2.2 events per year, respectively; $p=0.0021$ ). Furthermore, treatment convenience, as measured by the Treatment Satisfaction Questionnaire for Medication-9 (TSQM-9) convenience subscale, was improved for patients switching from GA $20 \mathrm{mg} /$ $\mathrm{mL}$ once daily to the three times weekly formulation 
[94]. Recently, results from the extension phase of the GLACIER study confirm the safety profile of the $40 \mathrm{mg} /$ $\mathrm{mL}$ three times weekly formulation, in terms of both IRAEs and convenience [113].

\section{Conclusions}

The availability of multiple drugs has totally changed the scenario of MS treatment. Treatment choices became much more complicated and decisions should be based on the combination of the efficacy and safety profiles. From this point of view GA associates a favourable efficacy profile, confirmed by more than 20 years of clinical use, with an excellent safety and tolerability profile. The burden of daily injections has been recently reduced by the availability of the new $40 \mathrm{mg} / \mathrm{mL}$ three times a week formulation, which has been shown to share the same efficacy of the $20 \mathrm{mg} / \mathrm{mL}$ once daily formulation, but with obvious advantages in terms of patient convenience.

GA has been classified as a first-line drug for the treatment of RRMS in Europe, with a clear indication both in naïve patients and in patients who discontinue other therapies for safety or tolerability issues. The recent evidence of the importance of personalized treatment implies that the assessment of the individual prognostic profile should drive treatment decisions, at the same time considering also patients' preference and convenience. Patients with a good prognostic profile as indicated by low disease activity - revealed by low brain lesion burden and few or absent active lesions at the time of treatment onset - may have a high probability of responding to first-line therapies, including GA. On the contrary, patients with very active disease in the early phases tend to require an induction approach to obtain a positive response to treatment.

Considering the choice among first-line therapies, GA offers an obvious advantage in young, potentially fertile women for the favourable safety profile in this population, as discussed above [107]. Patients with CIS are also expected to benefit from GA, given the evidence of efficacy in such patients, supported by extension studies showing clear protection from brain atrophy $[86,87]$. Another possible use of GA is as maintenance treatment in patients who start with an induction approach because of a negative prognostic profile. Induction therapy has often the advantage of "reshaping" the immune system, which can then be maintained by GA $[114,115]$.

The classification of MS clinical courses [2] defines the importance of disease activity not only in RRMS, but also in patients with a progressive disease course. The presence of disease activity represents a clear target for DMTs. Among them, the use of GA should be considered because of the long-term safety and absence of negative impact on spasticity, a frequent $\mathrm{AE}$ of IFN- $\beta$ treatment in this population. It should be noted, however, that conclusive data from clinical trials demonstrating the efficacy of GA in these patients are currently lacking.

We anticipate that the new $40 \mathrm{mg} / \mathrm{mL}$ three times weekly regimen might increase compliance and adherence. Therefore it is recommended that, in all consenting patients currently treated with the once daily formulation, the switch to the new formulation should be considered. An early start of GA treatment should be considered in the light of data on brain atrophy from the PreCISe study [87]: there was a significant $(-28 \% ; p=0.0209)$ difference when comparing early GA treatment versus delayed GA treatment.

In conclusion, clinical trials and real-life studies have consistently shown the efficacy and safety of both formulations of GA in the first-line treatment of patients with RRMS and for delaying the onset of clinically definite MS in patients with CIS. Overall, data suggest that while many types of patients can be expected to benefit from GA, the "ideal" subject would be one with RR disease or newly-diagnosed, young and active, wanting to lead a normal life. The use of GA for more than two decades shows a reassuring safety profile and optimal tolerability. The major concern may be the frequency of administration, an issue that the new formulation can be expected to minimize, contributing to the use of this drug. Besides patient convenience, the fact that no complex clinical monitoring is required during treatment clearly represents another strong point of the clinical use of GA.

\section{Abbreviations}

ARR: Annualized relapse rate; BDNF: Brain derived neurotrophic factor; CDMS: Clinically definite multiple sclerosis; CIS: Clinically isolated syndrome; CNS: Central nervous system; DMTs: Disease-modifying therapies;

EDSS: Expanded disability status scale; GA: Glatiramer acetate; IFN: Interferon; IRAEs: Injection-related adverse events; LTFU: Long-term follow up; MBP: Myelin basic protein; MHC: Major histocompatibility complex; MRI: Magnetic resonance imaging; MS: Multiple sclerosis; RRMS: Relapsingremitting multiple sclerosis; TNF: Tumour necrosis factor; TSQM-9: Treatment satisfaction questionnaire for medication-9.

\section{Competing interests}

GC has received honoraria as a consultant and for lecturing at scientific meetings from Novartis, Teva, Sanofi-Aventis, Genzyme, Merck Serono, Biogen, Bayer, Serono Symposia International Foundation, Excemed, Roche, Almirall, Chugai, Receptos and Forward Pharma.

$A B$ has received honoraria for serving in the scientific advisory boards of Almirall, Bayer, Biogen, Genzyme, with approval by the Director of AOU San Luigi University Hospital, and has received speaker honoraria from Biogen, Genzyme, Novartis, Teva; his institution has received grant support from Bayer, Biogen, Merck, Novartis, Teva, from the Italian Multiple Sclerosis Society, Fondazione Ricerca Biomedica ONLUS and San Luigi ONLUS. $\mathrm{DC}$ is an Advisory Board member of Almirall, Bayer Schering, Biogen, Genzyme, GW Pharmaceuticals, Merck Serono, Novartis, Teva and received honoraria for speaking or consultation fees from Almirall, Bayer Schering, Biogen Idec, Genzyme, GW Pharmaceuticals, Merck Serono, Novartis, SanofiAventis, Teva. He is also an external expert consultant of the European Medicine Agency (EMA), and the principal investigator in clinical trials for Bayer Schering, Biogen Idec, Merck Serono, Mitsubishi, Novartis, Roche, Sanofi-Aventis, Teva. His preclinical and clinical research was supported by grants from Bayer, Biogen, Merck Serono, Novartis and Teva. 
NDS has received honoraria or consultation fees from Novartis, Merck Serono, Biogen Idec, La Roche; has been member of Advisory Boards for Novartis, Merck Serono, Biogen Idec; has participated in company-sponsored speaker's bureau for Novartis, Merck Serono, Biogen Idec; has received travel reimbursements from Novartis, Merck Serono and Biogen Idec.

CF has received grants and personal fees from Teva, and grants from Merck Serono, Novartis and Fondazione Italiana Sclerosi Multipla.

AG serves on scientific advisory boards or as consultant for Merck Serono, Teva, Novartis, Biogen Idec; he has received honoraria for lecturing from Merck Serono, Biogen Idec, Novartis, Teva, Genzyme, Almirall.

PG is an Advisory Board member of Almirall, Biogen Italy, Sanofi-Genzyme, GW Pharmaceuticals, Merck Serono, Novartis, Teva and received honoraria for speaking or consultation fees from Almirall, Biogen Idec, Genzyme, GW Pharmaceuticals, Merck Serono, Novartis, Sanofi-Aventis, Teva. He is also an external expert consultant of the European Medicine Agency (EMA), and has been the principal investigator in clinical trials for Biogen Idec, Merck Serono, Novartis, Roche, Sanofi-Aventis, Teva, Almirall. His preclinical and clinical research was supported by grants from Bayer-Shering, Biogen-Idec, Merck-Serono, Novartis and Teva.

GLM has received honoraria for lecturing, travel expenses reimbursements for attending meetings, and financial support for research from Bayer Schering, Biogen Idec, Genzyme, Merck Serono, Novartis, Sanofi-Aventis and Teva. EM has received grants from Teva and Novartis and speaker honoraria from Biogen.

FP has received fees for speaking and advisory board activities by Almirall, Bayer, Biogen, Merck, Novartis, Sanofi-Genzyme and Teva.

CP has served on scientific advisory boards for Novartis, Merck Serono, Biogen Idec, Sanofi-Aventis, Genzyme, Almirall and Bayer, has received funding for travel and speaker honoraria from Sanofi-Aventis, Biogen Idec, Bayer, Teva, Merck Serono, Almirall, Genzyme, Actelion and Novartis, and receives research support from Novartis, Merck Serono, Biogen Idec, Bayer and Sanofi-Aventis.

MS receives research support and has received fees as speaker from SanofiAventis, Biogen, Bayer Schering and Merck Serono.

GT has received grants and personal fees from Teva, Novartis, Merck Serono, Abbvie and Abbott.

MT has served on scientific Advisory Boards for Biogen Idec, Novartis, Almirall, Roche and Genzyme; has received speaker honoraria from Biogen Idec, Bayer-Schering, Sanofi Aventis, Merck Serono, Teva, Genzyme, Almirall and Novartis; has received research grants for her Institution from Biogen Idec, Merck Serono and Novartis.

The other Authors declare no conflicts of interest.

\section{Authors' contributions}

All the authors critically contributed to the draft and subsequent reviews of the manuscript and approved the final version before submission.

\section{Acknowledgments}

We wish to thank Marie Cheeseman who provided medical writing assistance on behalf of Springer Healthcare Communications. This assistance was funded by Teva.

\section{Author details}

${ }^{1}$ Department of Neurology, INSPE, San Raffaele Scientific Institute, Via Olgettina 48, 20132 Milan, Italy. ${ }^{2}$ Department NEUROFARBA, Section Neurosciences, University of Florence, Florence, Italy. ${ }^{3}$ Neurology 2-CRESM (Multiple Sclerosis Regional Reference Center), AOU San Luigi Gonzaga, Orbassano, TO, Italy. ${ }^{4}$ Clinica Neurologica, Dipartimento di Medicina dei Sistemi, Università Tor Vergata, Rome, Italy. ${ }^{5}$ IRCCS Istituto Neurologico Mediterraneo (INM) Neuromed Pozzilli, Pozzilli, IS, Italy. ${ }^{6}$ Department of Neurological and Behavioural Sciences, University of Siena, Siena, Italy. ${ }^{7}$ Department of Neuroscience, INSPE, San Raffaele Scientific Institute, Milan, Italy. ${ }^{8}$ Department of Neurosciences DNS, The Multiple Sclerosis Centre Veneto Region (CeSMuV), University Hospital of Padova, Padova, Italy. ${ }^{9}$ Multiple Sclerosis Study Center, Hospital of Gallarate, Gallarate, VA, Italy. ${ }^{10}$ Neurology Unit, Fondazione Istituto San Raffaele "G. Giglio" di Cefalù, Cefalù, PA, Italy. ${ }^{11}$ Department of Neuroscience, Rehabilitation, Ophthalmology, Genetics, Maternal and Child Health, University of Genoa, Genoa, Italy. ${ }^{12}$ Department of Medical Sciences, Multiple Sclerosis Center, University of Cagliari, Cagliari, Italy. ${ }^{13}$ Neurology Unit, AUSL Parma - Fidenza Hospital, Fidenza, PR, Italy. ${ }^{14}$ Department of Medical and Surgical Sciences and Advanced Technologies, G.F. Ingrassia, Multiple Sclerosis Center, University of Catania, Catania, Italy. ${ }^{15}$ Department of Neurology and Psychiatry, Sapienza University of Rome, Rome, Italy. ${ }^{16}$ Department of Experimental and Clinical Medicine, 1 Neurological Clinic, Marche Polytechnic University, Ancona, Italy. ${ }^{17}$ Centre for Experimental Neurological Therapies (CENTERS), S. Andrea Hospital Site, Sapienza University of Rome, Rome, Italy. ${ }^{18}$ Department of Medical, Surgical, Neurological, Metabolic and Aging Sciences, Second University of Naples, Naples, Italy. ${ }^{19}$ Department of Basic Medical Sciences, Neuroscience and Sense Organs, University of Bari, Bari, Italy.

Received: 2 November 2015 Accepted: 11 April 2016 Published online: 04 July 2016

\section{References}

1. Nylander A, Hafler DA. Multiple sclerosis. J Clin Invest. 2012;122(4):1180-8. doi:10.1172/JCl58649.

2. Lublin FD. New multiple sclerosis phenotypic classification. Eur Neurol. 2014; 72 Suppl 1:1-5. doi:10.1159/000367614.

3. Cohen JA, Rae-Grant A. Handbook of Multiple Sclerosis. 2nd ed. London: Springer Healthcare; 2012.

4. Richards RG, Sampson FC, Beard SM, Tappenden P. A review of the natural history and epidemiology of multiple sclerosis: implications for resource allocation and health economic models. Health Technol Assess. 2002;6(10):1-73.

5. Abramsky O, Teitelbaum D, Arnon R. Effect of a synthetic polypeptide (COP 1) on patients with multiple sclerosis and with acute disseminated encephalomeylitis. Preliminary report. J Neurol Sci. 1977;31(3):433-8.

6. Bornstein MB, Miller Al, Teitelbaum D, Arnon R, Sela M. Multiple sclerosis: trial of a synthetic polypeptide. Ann Neurol. 1982;11(3):317-9. doi:10.1002/ ana.410110314.

7. Teva Pharmaceuticals Ltd. Copaxone ${ }^{\oplus} 20$ mg/ml Solution for Injection, Pre-filled Syringe 2003. http://www.mhra.gov.uk/home/groups/par/ documents/websiteresources/con025676.pdf. Accessed 14 Apr 2016.

8. Khan O, Rieckmann P, Boyko A, Selmaj K, Zivadinov R. Three times weekly glatiramer acetate in relapsing-remitting multiple sclerosis. Ann Neurol. 2013;73(6):705-13. doi:10.1002/ana.23938.

9. Aharoni R. The mechanism of action of glatiramer acetate in multiple sclerosis and beyond. Autoimmun Rev. 2013;12(5):543-53. doi:10.1016/j. autrev.2012.09.005.

10. Arnon R, Aharoni R. Mechanism of action of glatiramer acetate in multiple sclerosis and its potential for the development of new applications. Proc Natl Acad Sci U S A. 2004;101 Suppl 2:14593-8. doi:10.1073/pnas.0404887101.

11. Arnon R, Aharoni R. Neurogenesis and neuroprotection in the CNSfundamental elements in the effect of Glatiramer acetate on treatment of autoimmune neurological disorders. Mol Neurobiol. 2007;36(3):245-53. doi: 10.1007/s12035-007-8002-z

12. Farina C, Weber MS, Meinl E, Wekerle H, Hohlfeld R. Glatiramer acetate in multiple sclerosis: update on potential mechanisms of action. Lancet Neurol. 2005;4(9):567-75. doi:10.1016/S1474-4422(05)70167-8.

13. Messina S, Patti F. The pharmacokinetics of glatiramer acetate for multiple sclerosis treatment. Expert Opin Drug Metab Toxicol. 2013;9(10):1349-59. doi:10.1517/17425255.2013.811489.

14. Arnon R. The development of Cop 1 (Copaxone), an innovative drug for the treatment of multiple sclerosis: personal reflections. Immunol Lett. 1996; 50(1-2):1-15.

15. Teitelbaum D, Meshorer A, Hirshfeld T, Arnon R, Sela M. Suppression of experimental allergic encephalomyelitis by a synthetic polypeptide. Eur J Immunol. 1971;1(4):242-8. doi:10.1002/eji.1830010406.

16. Teitelbaum D, Aharoni R, Arnon R, Sela M. Specific inhibition of the T-cell response to myelin basic protein by the synthetic copolymer Cop 1. Proc Natl Acad Sci U S A. 1988;85(24):9724-8.

17. Teitelbaum D, Milo R, Arnon R, Sela M. Synthetic copolymer 1 inhibits human T-cell lines specific for myelin basic protein. Proc Natl Acad Sci U S A. 1992;89(1):137-41.

18. Aharoni R, Teitelbaum D, Arnon R, Sela M. Copolymer 1 acts against the immunodominant epitope 82-100 of myelin basic protein by T cell receptor antagonism in addition to major histocompatibility complex blocking. Proc Natl Acad Sci U S A. 1999;96(2):634-9.

19. Neuhaus O, Farina C, Yassouridis A, Wiendl H, Then Bergh F, Dose T, et al Multiple sclerosis: comparison of copolymer-1- reactive $T$ cell lines from 
treated and untreated subjects reveals cytokine shift from T helper 1 to T helper 2 cells. Proc Natl Acad Sci U S A. 2000:97(13):7452-7.

20. Aharoni R, Teitelbaum D, Sela M, Arnon R. Bystander suppression of experimental autoimmune encephalomyelitis by $T$ cell lines and clones of the Th2 type induced by copolymer 1. J Neuroimmunol. 1998;91(1-2):135-46.

21. Duda PW, Schmied MC, Cook SL, Krieger JI, Hafler DA. Glatiramer acetate (Copaxone) induces degenerate, Th2-polarized immune responses in patients with multiple sclerosis. J Clin Invest. 2000;105(7):967-76. doi:10. 1172/JCl8970

22. Farina $C$, Then Bergh F, Albrecht $H$, Meinl E, Yassouridis A, Neuhaus $O$, et al. Treatment of multiple sclerosis with Copaxone (COP): Elispot assay detects COP-induced interleukin-4 and interferon-gamma response in blood cells. Brain. 2001;124(Pt 4):705-19.

23. Farina C, Wagenpfeil S, Hohlfeld R. Immunological assay for assessing the efficacy of glatiramer acetate (Copaxone) in multiple sclerosis. A pilot study. J Neurol. 2002;249(11):1587-92. doi:10.1007/s00415-002-0904-0.

24. Miller A, Shapiro S, Gershtein R, Kinarty A, Rawashdeh H, Honigman S, et al. Treatment of multiple sclerosis with copolymer-1 (Copaxone): implicating mechanisms of Th1 to Th2/Th3 immune-deviation. J Neuroimmunol. 1998; 92(1-2):113-21.

25. Chen M, Gran B, Costello K, Johnson K, Martin R, Dhib-Jalbut S. Glatiramer acetate induces a Th2-biased response and crossreactivity with myelin basic protein in patients with MS. Mult Scler. 2001;7(4):209-19.

26. Chen M, Conway K, Johnson KP, Martin R, Dhib-Jalbut S. Sustained immunological effects of Glatiramer acetate in patients with multiple sclerosis treated for over 6 years. J Neurol Sci. 2002;201(1-2):71-7.

27. Oreja-Guevara C, Ramos-Cejudo J, Aroeira LS, Chamorro B, Diez-Tejedor E. $\mathrm{TH} 1 / \mathrm{TH} 2$ Cytokine profile in relapsing-remitting multiple sclerosis patients treated with Glatiramer acetate or Natalizumab. BMC Neurol. 2012;12:95. doi: 10.1186/1471-2377-12-95

28. Becher B, Segal BM. T(H)17 cytokines in autoimmune neuro-inflammation. Curr Opin Immunol. 2011;23(6):707-12. doi:10.1016/j.coi.2011.08.005.

29. Jadidi-Niaragh F, Mirshafiey A. Th17 cell, the new player of neuroinflammatory process in multiple sclerosis. Scand J Immunol. 2011; 74(1):1-13. doi:10.1111/j.1365-3083.2011.02536.x.

30. Tzartos JS, Friese MA, Craner MJ, Palace J, Newcombe J, Esiri MM, et al. Interleukin-17 production in central nervous system-infiltrating $T$ cells and glial cells is associated with active disease in multiple sclerosis. Am J Pathol. 2008;172(1):146-55. doi:10.2353/ajpath.2008.070690.

31. Aharoni R, Eilam R, Stock A, Vainshtein A, Shezen E, Gal H, et al. Glatiramer acetate reduces Th-17 inflammation and induces regulatory T-cells in the CNS of mice with relapsing-remitting or chronic EAE. J Neuroimmunol. 2010;225(1-2):100-11. doi:10.1016/j.jneuroim.2010.04.022.

32. Begum-Haque S, Sharma A, Kasper IR, Foureau DM, Mielcarz DW, Haque A et al. Downregulation of IL-17 and IL-6 in the central nervous system by glatiramer acetate in experimental autoimmune encephalomyelitis. J Neuroimmunol. 2008;204(1-2):58-65. doi:10.1016/j.jneuroim.2008.07.018.

33. Miyara M, Gorochov G, Ehrenstein M, Musset L, Sakaguchi S, Amoura Z. Human FoxP3+ regulatory T cells in systemic autoimmune diseases. Autoimmun Rev. 2011;10(12):744-55. doi:10.1016/j.autrev.2011.05.004.

34. Viglietta V, Baecher-Allan C, Weiner HL, Hafler DA. Loss of functional suppression by CD4 + CD25+ regulatory T cells in patients with multiple sclerosis. J Exp Med. 2004;199(7):971-9. doi:10.1084/jem.20031579.

35. Huan J, Culbertson N, Spencer L, Bartholomew R, Burrows GG, Chou YK, et al. Decreased FOXP3 levels in multiple sclerosis patients. J Neurosci Res. 2005;81(1):45-52. doi:10.1002/jnr.20522.

36. Hong J, Li N, Zhang X, Zheng B, Zhang JZ. Induction of CD4 + CD25+ regulatory $T$ cells by copolymer-l through activation of transcription factor Foxp3. Proc Natl Acad Sci U S A. 2005;102(18):6449-54. doi:10.1073/pnas. 0502187102.

37. Haas J, Korporal M, Balint B, Fritzsching B, Schwarz A, Wildemann B. Glatiramer acetate improves regulatory T-cell function by expansion of naive CD4(+)CD25(+)FOXP3(+)CD31(+) T-cells in patients with multiple sclerosis. J Neuroimmunol. 2009;216(1-2):113-7. doi:10.1016/j.jneuroim.2009.06.011.

38. Farina C, Vargas V, Heydari N, Kumpfel T, Meinl E, Hohlfeld R. Treatment with glatiramer acetate induces specific lgG4 antibodies in multiple sclerosis patients. J Neuroimmunol. 2002;123(1-2):188-92.

39. Vieira PL, Heystek HC, Wormmeester J, Wierenga EA, Kapsenberg ML. Glatiramer acetate (copolymer-1, copaxone) promotes Th2 cell development and increased IL-10 production through modulation of dendritic cells. J Immunol. 2003;170(9):4483-8.
40. Kim HJ, Ifergan I, Antel JP, Seguin R, Duddy M, Lapierre Y, et al. Type 2 monocyte and microglia differentiation mediated by glatiramer acetate therapy in patients with multiple sclerosis. J Immunol. 2004;172(11):7144-53.

41. Carpintero R, Brandt KJ, Gruaz L, Molnarfi N, Lalive PH, Burger D. Glatiramer acetate triggers PI3Kdelta/Akt and MEK/ERK pathways to induce IL-1 receptor antagonist in human monocytes. Proc Natl Acad Sci U S A. 2010; 107(41):17692-7. doi:10.1073/pnas.1009443107.

42. Weber MS, Prod'homme T, Youssef S, Dunn SE, Rundle CD, Lee L, et al. Type II monocytes modulate $T$ cell-mediated central nervous system autoimmune disease. Nat Med. 2007;13(8):935-43. doi:10.1038/nm1620.

43. Weber MS, Starck M, Wagenpfeil S, Meinl E, Hohlfeld R, Farina C. Multiple sclerosis: glatiramer acetate inhibits monocyte reactivity in vitro and in vivo. Brain. 2004;127(Pt 6):1370-8. doi:10.1093/brain/awh163.

44. Aharoni R, Kayhan B, Eilam R, Sela M, Arnon R. Glatiramer acetate-specific T cells in the brain express $T$ helper 2/3 cytokines and brain-derived neurotrophic factor in situ. Proc Natl Acad Sci U S A. 2003;100(24):14157-62. doi:10.1073/pnas.2336171100.

45. Gentile A, Rossi S, Studer V, Motta C, De Chiara V, Musella A, et al. Glatiramer acetate protects against inflammatory synaptopathy in experimental autoimmune encephalomyelitis. J Neuroimmune Pharmacol. 2013:8(3):651-63. doi:10.1007/s11481-013-9436-x.

46. Skihar V, Silva C, Chojnacki A, Doring A, Stallcup WB, Weiss S, et al. Promoting oligodendrogenesis and myelin repair using the multiple sclerosis medication glatiramer acetate. Proc Natl Acad Sci U S A. 2009; 106(42):17992-7. doi:10.1073/pnas.0909607106.

47. Arnold DL, Narayanan S, Antel S. Neuroprotection with glatiramer acetate: evidence from the PreCISe trial. J Neurol. 2013;260(7):1901-6. doi:10.1007/ s00415-013-6903-5.

48. Filippi M, Rovaris M, Rocca MA, Sormani MP, Wolinsky JS, Comi G. Glatiramer acetate reduces the proportion of new MS lesions evolving into "black holes". Neurology. 2001;57(4):731-3.

49. Zivadinov R, Dwyer M, Barkay H, Steinerman JR, Knappertz V, Khan O. Effect of glatiramer acetate three-times weekly on the evolution of new, active multiple sclerosis lesions into T1-hypointense "black holes": a post hoc magnetic resonance imaging analysis. J Neurol. 2015;262(3):648-53. doi:10.1007/s00415-014-7616-0.

50. Cohen JA, Rovaris M, Goodman AD, Ladkani D, Wynn D, Filippi M. Randomized, double-blind, dose-comparison study of glatiramer acetate in relapsing-remitting MS. Neurology. 2007;68(12):939-44. doi:10.1212/01.wnl. 0000257109.61671 .06

51. Comi G, Cohen JA, Arnold DL, Wynn D, Filippi M. Phase III dose-comparison study of glatiramer acetate for multiple sclerosis. Ann Neurol. 2011;69(1):75-82. doi:10.1002/ana.22316.

52. Filippi M, Wolinsky JS, Comi G. Effects of oral glatiramer acetate on clinical and MRI-monitored disease activity in patients with relapsing multiple sclerosis: a multicentre, double-blind, randomised, placebocontrolled study. Lancet Neurol. 2006:5(3):213-20. doi:10.1016/S14744422(06)70327-1.

53. Johnson KP, Brooks BR, Cohen JA, Ford CC, Goldstein J, Lisak RP, et al. Copolymer 1 reduces relapse rate and improves disability in relapsingremitting multiple sclerosis: results of a phase III multicenter, double-blind placebo-controlled trial. Neurology. 1995;45(7):1268-76.

54. Comi G, Filippi M, Wolinsky JS. European/Canadian multicenter, doubleblind, randomized, placebo-controlled study of the effects of glatiramer acetate on magnetic resonance imaging-measured disease activity and burden in patients with relapsing multiple sclerosis. European/Canadian Glatiramer Acetate Study Group. Ann Neurol. 2001;49(3):290-7.

55. Bornstein MB, Miller A, Slagle S, Weitzman M, Crystal H, Drexler E, et al A pilot trial of Cop 1 in exacerbating-remitting multiple sclerosis. N Engl J Med. 1987:317(7):408-14. doi:10.1056/NEJM198708133170703.

56. Sormani MP, Rovaris M, Valsasina P, Wolinsky JS, Comi G, Filippi M. Measurement error of two different techniques for brain atrophy assessment in multiple sclerosis. Neurology. 2004;62(8):1432-4.

57. Mikol DD, Barkhof F, Chang P, Coyle PK, Jeffery DR, Schwid SR, et al. Comparison of subcutaneous interferon beta-1a with glatiramer acetate in patients with relapsing multiple sclerosis (the REbif vs Glatiramer Acetate in Relapsing MS Disease [REGARD] study): a multicentre, randomised, parallel, open-label trial. Lancet Neurol. 2008;7(10):903-14. doi:10.1016/S14744422(08)70200-X.

58. Cadavid D, Wolansky $\sqcup$, Skurnick J, Lincoln J, Cheriyan J, Szczepanowski K, et al. Efficacy of treatment of MS with IFNbeta-1b or glatiramer acetate by monthly 
brain MRI in the BECOME study. Neurology. 2009;72(23):1976-83. doi:10.1212/01. wnl.0000345970.73354.17.

59. O'Connor P, Filippi M, Arnason B, Comi G, Cook S, Goodin D, et al. 250 microg or 500 microg interferon beta-1b versus $20 \mathrm{mg}$ glatiramer acetate in relapsing-remitting multiple sclerosis: a prospective, randomised, multicentre study. Lancet Neurol. 2009;8(10):889-97. doi:10.1016/S14744422(09)70226-1.

60. Fox RJ, Miller DH, Phillips JT, Hutchinson M, Havrdova E, Kita M, et al. Placebo-controlled phase 3 study of oral BG-12 or glatiramer in multiple sclerosis. N Engl J Med. 2012;367(12):1087-97. doi:10.1056/NEJMoa1206328.

61. Hutchinson M, Fox RJ, Miller DH, Phillips JT, Kita M, Havrdova E, et al. Clinical efficacy of BG-12 (dimethyl fumarate) in patients with relapsing-remitting multiple sclerosis: subgroup analyses of the CONFIRM study. J Neurol. 2013; 260(9):2286-96. doi:10.1007/s00415-013-6968-1.

62. La Mantia L, Di Pietrantonj C, Rovaris M, Rigon G, Frau S, Berardo F, et al. Comparative efficacy of interferon beta versus glatiramer acetate for relapsing-remitting multiple sclerosis. J Neurol Neurosurg Psychiatry. 2015; 86(9):1016-20. doi:10.1136/jnnp-2014-309243.

63. Ford C, Goodman AD, Johnson K, Kachuck N, Lindsey JW, Lisak R, et al. Continuous long-term immunomodulatory therapy in relapsing multiple sclerosis: results from the 15-year analysis of the US prospective open-label study of glatiramer acetate. Mult Scler. 2010;16(3):342-50. doi:10.1177/ 1352458509358088

64. Ford C, Ladkani D, editors. Twenty years of continuous treatment of multiple sclerosis with glatiramer acetate $20 \mathrm{mg}$ daily: long-term clinical results of the US open-label extension study. 29th Congress of the European Committee for Treatment and Research in Multiple Sclerosis and 18th Annual Conference of Rehabilitation in Multiple Sclerosis; 2013 October 2-5; Copenhagen, Denmark

65. Ford CC, Johnson KP, Lisak RP, Panitch HS, Shifronis G, Wolinsky JS. A prospective open-label study of glatiramer acetate: over a decade of continuous use in multiple sclerosis patients. Mult Scler. 2006;12(3):309-20.

66. Johnson KP, Brooks BR, Cohen JA, Ford CC, Goldstein J, Lisak RP, et al. Extended use of glatiramer acetate (Copaxone) is well tolerated and maintains its clinical effect on multiple sclerosis relapse rate and degree of disability. Copolymer 1 Multiple Sclerosis Study Group. Neurology. 1998;50(3):701-8.

67. Johnson KP, Brooks BR, Ford CC, Goodman AD, Lisak RP, Myers LW, et al. Glatiramer acetate (Copaxone): comparison of continuous versus delayed therapy in a six-year organized multiple sclerosis trial. Mult Scler. 2003;9(6): 585-91.

68. Johnson KP, Ford CC, Lisak RP, Wolinsky JS. Neurologic consequence of delaying glatiramer acetate therapy for multiple sclerosis: 8-year data. Acta Neurol Scand. 2005;111(1):42-7. doi:10.1111/j.1600-0404.2004.00351.x.

69. Wolinsky JS, Narayana PA, Johnson KP. United States open-label glatiramer acetate extension trial for relapsing multiple sclerosis: MRI and clinical correlates. Multiple Sclerosis Study Group and the MRI Analysis Center. Mult Scler. 2001;7(1):33-41.

70. Rovaris M, Comi G, Rocca MA, Valsasina P, Ladkani D, Pieri E, et al. Long-term follow-up of patients treated with glatiramer acetate: a multicentre, multinational extension of the European/Canadian double-blind, placebo-controlled, MRI-monitored trial. Mult Scler. 2007;13(4):502-8. doi:10.1177/1352458506070704.

71. Wolinsky JS, Comi G, Filippi M, Ladkani D, Kadosh S, Shifroni G. Copaxone's effect on MRI-monitored disease in relapsing MS is reproducible and sustained. Neurology. 2002;59(8):1284-6.

72. Arnal-Garcia C, Amigo-Jorrin Mdel C, Lopez-Real AM, Lema-Devesa C, Llopis $\mathrm{N}$, Sanchez-de la Rosa R. Long-term effectiveness of glatiramer acetate in clinical practice conditions. J Clin Neurosci. 2014;21 (12):2212-8. doi:10.1016/ j.jocn.2014.05.045

73. Kalincik T, Jokubaitis V, Izquierdo G, Duquette $P$, Girard $M$, Grammond $P$, et al. Comparative effectiveness of glatiramer acetate and interferon beta formulations in relapsing-remitting multiple sclerosis. Mult Scler. 2015;21(9): 1159-71. doi:10.1177/1352458514559865.

74. Khan O, Bao F, Shah M, Caon C, Tselis A, Bailey R, et al. Effect of diseasemodifying therapies on brain volume in relapsing-remitting multiple sclerosis: results of a five-year brain MRI study. J Neurol Sci. 2012;312(1-2):712. doi:10.1016/j.jns.2011.08.034

75. Bergvall N, Makin C, Lahoz R, Agashivala N, Pradhan A, Capkun G, et al. Comparative effectiveness of fingolimod versus interferons or glatiramer acetate for relapse rates in multiple sclerosis: a retrospective US claims database analysis. Curr Med Res Opin. 2013;29(12):1647-56. doi:10.1185/ 03007995.2013.847411.

76. Gobbi C, Zecca C, Linnebank M, Muller S, You X, Meier R, et al. Swiss analysis of multiple sclerosis: a multicenter, non-interventional, retrospective cohort study of disease-modifying therapies. Eur Neurol. 2013;70(1-2):35-41. doi:10.1159/000346761.

77. Jongen PJ, Lehnick D, Sanders E, Seeldrayers P, Fredrikson S, Andersson M, et al. Health-related quality of life in relapsing remitting multiple sclerosis patients during treatment with glatiramer acetate: a prospective, observational, international, multi-centre study. Health Qual Life Outcomes. 2010;8:133. doi:10.1186/1477-7525-8-133.

78. Ziemssen T, Hoffman J, Apfel R, Kern S. Effects of glatiramer acetate on fatigue and days of absence from work in first-time treated relapsingremitting multiple sclerosis. Health Qual Life Outcomes. 2008;6:67. doi:10. 1186/1477-7525-6-67.

79. Ghezzi A, Amato MP, Annovazzi P, Capobianco M, Gallo P, La Mantia L, et al. Long-term results of immunomodulatory treatment in children and adolescents with multiple sclerosis: the Italian experience. Neurol Sci. 2009; 30(3):193-9. doi:10.1007/s10072-009-0083-1.

80. Kornek B, Bernert G, Balassy C, Geldner J, Prayer D, Feucht M. Glatiramer acetate treatment in patients with childhood and juvenile onset multiple sclerosis. Neuropediatrics. 2003;34(3):120-6. doi:10.1055/s-2003-41274.

81. Caon C, Din M, Ching W, Tselis A, Lisak R, Khan O. Clinical course after change of immunomodulating therapy in relapsing-remitting multiple sclerosis. Eur J Neurol. 2006;13(5):471-4. doi:10.1111/j.1468-1331.2006.01273.x.

82. Zwibel HL. Glatiramer acetate in treatment-naive and prior interferon-beta1b-treated multiple sclerosis patients. Acta Neurol Scand. 2006;113(6):378-86. doi:10.1111/j.1600-0404.2006.00627.x.

83. Ziemssen T, Bajenaru OA, Carra A, de Klippel N, de Sa JC, Edland A, et al. A 2-year observational study of patients with relapsing-remitting multiple sclerosis converting to glatiramer acetate from other disease-modifying therapies: the COPTIMIZE trial. J Neurol. 2014;261(11):2101-11. doi:10.1007/ s00415-014-7446-0.

84. Lublin FD, Cofield SS, Cutter GR, Conwit R, Narayana PA, Nelson F, et al. Randomized study combining interferon and glatiramer acetate in multiple sclerosis. Ann Neurol. 2013:73(3):327-40, doi:10.1002/ana.23863.

85. Goodman AD, Rossman H, Bar-Or A, Miller A, Miller DH, Schmierer $\mathrm{K}$, et al. GLANCE: results of a phase 2, randomized, double-blind, placebocontrolled study. Neurology. 2009;72(9):806-12. doi:10.1212/01.wnl. 0000343880.13764.69.

86. Comi G, Martinelli V, Rodegher M, Moiola L, Bajenaru O, Carra A, et al. Effect of glatiramer acetate on conversion to clinically definite multiple sclerosis in patients with clinically isolated syndrome (PreCISe study): a randomised, double-blind, placebo-controlled trial. Lancet. 2009;374(9700):1503-11. doi: 10.1016/S0140-6736(09)61259-9.

87. Comi G, Martinelli V, Rodegher M, Moiola L, Leocani L, Bajenaru O, et al. Effects of early treatment with glatiramer acetate in patients with clinically isolated syndrome. Mult Scler. 2013;19(8):1074-83. doi:10.1177/ 1352458512469695.

88. Wolinsky JS, Narayana PA, O'Connor P, Coyle PK, Ford C, Johnson K, et al. Glatiramer acetate in primary progressive multiple sclerosis: results of a multinational, multicenter, double-blind, placebo-controlled trial. Ann Neurol. 2007;61(1):14-24. doi:10.1002/ana.21079.

89. Wolinsky JS, Shochat T, Weiss S, Ladkani D. Glatiramer acetate treatment in PPMS: why males appear to respond favorably. J Neurol Sci. 2009;286(1-2): 92-8. doi:10.1016/j.jns.2009.04.019.

90. Sajja BR, Narayana PA, Wolinsky JS, Ahn CW. Longitudinal magnetic resonance spectroscopic imaging of primary progressive multiple sclerosis patients treated with glatiramer acetate: multicenter study. Mult Scler. 2008; 14(1):73-80. doi:10.1177/1352458507079907.

91. Khan O, Rieckmann P, Boyko A, Selmaj K, Ashtamker N, Davis M, et al. Efficacy and safety of a three-times weekly dosing regimen of glatiramer acetate in relapsing-remitting multiple sclerosis patients: 3-year results of the Glatiramer Actetate Low-frequency Administration (GALA) open-label extension study [abstract]. Presented at the 67th American Academy of Neurology Annual Meeting. Washington, DC. April 18-24, 2015. Neurology. 2015;84(14 Suppl):P7.273

92. Cutter G, Wolinsky JS, Comi G, Ladkani D, Knappertz V, Vainstein A, et al. Comparable clinical and MRI efficacy of glatiramer acetate $40 \mathrm{mg} / \mathrm{mL}$ TIW and $20 \mathrm{mg} / \mathrm{mL}$ QD: results of a systematic review and meta-analysis [abstract no. P053]. Mult Scler. 2014;20 Suppl 1:90-1. 
93. Cutter G, Wolinsky JS, Comi G, Ladkani D, Knappertz V, Vainstein A, et al. Indirect comparison of glatiramer acetate $40 \mathrm{mg} / \mathrm{mL}$ TIW and $20 \mathrm{mg} / \mathrm{mL}$ QD dosing regimen effects on relapse rate: results of a predictive statistical model [abstract no. P100]. Mult Scler. 2014;20 Suppl 1:112.

94. Wolinsky JS, Borresen TE, Dietrich DW, Wynn D, Sidi Y, Steinerman JR, et al. GLACIER: An open-label, randomized, multicenter study to assess the safety and tolerability of glatiramer acetate $40 \mathrm{mg}$ three-times weekly versus 20 mg daily in patients with relapsing-remitting multiple sclerosis. Mult Scler Relat Disord. 2015;4(4):370-6. doi:10.1016/j.msard.2015.06.005.

95. Meca-Lallana JE, Balseiro JJ, Lacruz F, Guijarro C, Sanchez O, Cano A, et al. Spasticity improvement in patients with relapsing-remitting multiple sclerosis switching from interferon-beta to glatiramer acetate: the ESCALA Study. J Neurol Sci. 2012;315(1-2):123-8. doi:10.1016/j.jns.2011.11.010.

96. Makhani N, Ngan BY, Kamath BM, Yeh EA. Glatiramer acetate-induced acute hepatotoxicity in an adolescent with MS. Neurology. 2013;81(9):850-2. doi: 10.1212/WNL.0b013e3182a2cc4a.

97. Antezana A, Herbert J, Park J, Kister I. Glatiramer acetate-induced acute hepatotoxicity in an adolescent with MS. Neurology. 2014;82(20):1846-7. doi:10.1212/01.wnl.0000450224.37865.80.

98. La Gioia S, Bacis G, Sonzogni A, Frigeni B, Conti MZ, Vedovello M, et al. Glatiramer acetate-induced hepatitis in a young female patient with multiple sclerosis. Mult Scler Relat Disord. 2014;3(6):732-4. doi:10.1016/j. msard.2014.08.001

99. Rauschka H, Farina C, Sator P, Gudek S, Breier F, Schmidbauer M. Severe anaphylactic reaction to glatiramer acetate with specific lgE. Neurology. 2005;64(8):1481-2. doi:10.1212/01.WNL.0000158675.01711.58.

100. Corominas M, Postigo I, Cardona V, Lleonart R, Romero-Pinel L, Martinez J. IgE-mediated allergic reactions after the first administration of glatiramer acetate in patients with multiple sclerosis. Int Arch Allergy Immunol. 2014; 165(4):244-6. doi:10.1159/000371418.

101. Ghezzi A, Banwell B, Boyko A, Amato MP, Anlar B, Blinkenberg M, et al. The management of multiple sclerosis in children: a European view. Mult Scler. 2010;16(10):1258-67. doi:10.1177/1352458510375568.

102. Chitnis T, Tenembaum S, Banwell B, Krupp L, Pohl D, Rostasy K, et al. Consensus statement: evaluation of new and existing therapeutics for pediatric multiple sclerosis. Mult Scler. 2012;18(1):116-27. doi:10.1177/ 1352458511430704.

103. Amato MP, Portaccio E. Fertility, pregnancy and childbirth in patients with multiple sclerosis: impact of disease-modifying drugs. CNS Drugs. 2015;29(3): 207-20. doi:10.1007/s40263-015-0238-y.

104. Fragoso YD. Glatiramer acetate to treat multiple sclerosis during pregnancy and lactation: a safety evaluation. Expert Opin Drug Saf. 2014;13(12):1743-8. doi:10.1517/14740338.2014.955849.

105. Ghezzi A, Annovazzi P, Portaccio E, Cesari E, Amato MP. Current recommendations for multiple sclerosis treatment in pregnancy and puerperium. Expert Rev Clin Immunol. 2013;9(7):683-91. doi:10.1586/ 1744666X.2013.811046. quiz 92.

106. Weber-Schoendorfer C, Schaefer C. Multiple sclerosis, immunomodulators, and pregnancy outcome: a prospective observational study. Mult Scler. 2009;15(9):1037-42. doi:10.1177/1352458509106543.

107. Giannini M, Portaccio E, Ghezzi A, Hakiki B, Pasto L, Razzolini L, et al. Pregnancy and fetal outcomes after glatiramer acetate exposure in patients with multiple sclerosis: a prospective observational multicentric study. BMC Neurol. 2012;12:124. doi:10.1186/1471-2377-12-124.

108. Fragoso YD, Finkelsztejn A, Kaimen-Maciel DR, Grzesiuk AK, Gallina AS, Lopes J, et al. Long-term use of glatiramer acetate by 11 pregnant women with multiple sclerosis: a retrospective, multicentre case series. CNS Drugs. 2010;24(11):969-76. doi:10.2165/11538960-000000000-00000.

109. US Food and Drug Administration. Content and format of labeling for human prescription drug and biological products: requirements for pregnancy and lactation labeling. 2015. http://www.fda.gov/downloads/ aboutfda/reportsmanualsforms/reports/economicanalyses/ucm427798.pdf. Accessed 21 Oct 2015

110. Confavreux C, Hutchinson M, Hours MM, Cortinovis-Tourniaire P, Moreau T. Rate of pregnancy-related relapse in multiple sclerosis. Pregnancy in Multiple Sclerosis Group. N Engl J Med. 1998;339(5):285-91. doi:10.1056/ NEJM199807303390501.

111. Balak DM, Hengstman GJ, Cakmak A, Thio HB. Cutaneous adverse events associated with disease-modifying treatment in multiple sclerosis: a systematic review. Mult Scler. 2012;18(12):1705-17. doi:10.1177/ 1352458512438239.
112. Watkins CE, Litchfield J, Youngberg G, Leicht SS, Krishnaswamy G. Glatiramer acetate-induced lobular panniculitis and skin necrosis. Cutis. 2015;95(3):E26-30.

113. Wynn DS, Kolodny S, Rubinchick S, Steinerman J, Knappertz V, Wolinsky J. Patient experience with glatiramer acetate $40 \mathrm{mg} / 1 \mathrm{~mL}$ three-times weekly treatment for relapsing-remitting multiple sclerosis: results from the GLACIER extension study [abstract]. Presented at the 67th American Academy of Neurology Annual Meeting. Washington, DC. April 18-24, 2015. Neurology. 2015;84(14 Suppl):P7.218.

114. Arnold DL, Campagnolo D, Panitch H, Bar-Or A, Dunn J, Freedman MS, et al. Glatiramer acetate after mitoxantrone induction improves MRI markers of lesion volume and permanent tissue injury in MS. J Neurol. 2008;255(10): 1473-8. doi:10.1007/s00415-008-0911-x.

115. Vollmer T, Panitch H, Bar-Or A, Dunn J, Freedman MS, Gazda SK, et al. Glatiramer acetate after induction therapy with mitoxantrone in relapsing multiple sclerosis. Mult Scler. 2008;14(5):663-70. doi:10.1177/ 1352458507085759.

116. Lindsey JW, Scott TF, Lynch SG, Cofield SS, Nelson F, Conwit R, et al. The CombiRx trial of combined therapy with interferon and glatirame acetate in relapsing remitting MS: Design and baseline characteristics. Mult Scler Relat Disord. 2012;1(2):81-6. doi:10.1016/j.msard.2012.01.006.

\section{Submit your next manuscript to BioMed Central and we will help you at every step:}

- We accept pre-submission inquiries

- Our selector tool helps you to find the most relevant journal

- We provide round the clock customer support

- Convenient online submission

- Thorough peer review

- Inclusion in PubMed and all major indexing services

- Maximum visibility for your research

Submit your manuscript at www.biomedcentral.com/submit

BioMed Central 